\title{
SYSTEM OF THE COMPLICATED PRACTICAL PROBLEMS ANALYSIS
}

\author{
A.V. KOLESNIKOV and O.P. FEDOROV \\ Kaliningrad State Technical University \\ Kaliningrad 236000, Soviet prospect 1, Russia \\ E-mail: Kolesnikov@baltnet.ru, fedorovoleg@europe.com
}

Received October 4, 2001

\begin{abstract}
The original methodology of the system analysis of the inhomogeneous problem is offered, including stages of its reducing to homogeneous parts and selecting for them appropriate toolkits: methods and models. This system applies the accumulated knowledge and the experts skills to refer of each homogeneous problem to one or several alternative classes of modelling methods: analytical methods, statistical methods, artificial neuronets, knowledge based systems, fuzzy systems, genetic algorithms. The knowledge base testing has shown sufficiency and consistency of knowledge for realization of the inhomogeneous problems analysis even in conditions with a low and average distortion in the problem descriptions.
\end{abstract}

\section{INTRODUCTION}

The majority of the information processing and controlling problems in technical-organizational, bio-industrial, economic systems are so complicated, that it is either impossible, or ineffective to solve without the preliminary (prior) system analysis. If you have necessity to solve some problem, and the way of its solution "does not appear" in a head, that is a reason to consider such a problem as complicated. Different experts can differently represent both the problem, and a way of its decision. In such conditions, the attempt to solve of a problem without understanding of its heart in many respects resembles shooting from a bow by the closed eyes. It is possible, certainly, to hit the mark, but the probability of a miss is much higher. For avoidance of a similar situation also it is necessary to resort to the system analysis with the purpose of the better understanding of the given problem heart. The majority of modern analysis techniques are reductive, i.e. are constructed on a principle " Divide the problem on so much of parts, how many it is required, that they should be easy for solving " [Decart R.]. The original methodology of the system analysis of the inhomogeneous problem is offered in the given 
work, including stages of its reducing on homogeneous parts and selecting for them appropriate toolkits: methods and models. Thus ideal variant would be to use a single method (or even various methods from a single class) for solving of each received homogeneous problem. Unfortunately, in real life the majority of problems are so complicated, that it is impossible (or inefficient) to solve them using a single method [2]. Hence we must use several methods, i.e. to construct a hybrid $[1 ; 3]$. Unfortunately, the choice of concrete methods (and even classes of methods) is ambiguous and inconsistent process. So as there is no universal way of a choice of a concrete method (class of methods), the compelled way is a use of knowledge, based on world practice of using one or the other method. The system of the complicated practical problems analysis, based on knowledge, applies the knowledge, cumulated to the present time, and skills of the experts under the system analysis, systems of information processing and controlling to assign the problem to one or several methods from set of methods classes of modelling (the knowledge is submitted in producing form as more than 200 rules). The problem in the offered approach concerns not to a concrete method, but to a class of methods, that considerably simplifies a problem. On the other hand such solving the problem considerably simplifies the following choice of a concrete method inside the specified class. The system uses the information about six classes of methods: analytical methods, methods of imitating modelling, artificial neuronets (ANN), knowledge based systems (KBS), fuzzy systems (FS) and genetic algorithms (GA). The knowledge, needed for development of method, algorithm and the software, was taken and systematized from the more than 150 references (books, methodical literature, periodic press, engineering specifications from the software producers, promotional materials). Besides there were investigated the opinions of experts in analytical, imitating and heuristic methods of modelling (ANN, KBS, FS, GA) for solving the problems of decisions support. It is obvious, that the developing the knowledge base with generalization of the so numerous information, can result in inadequate results at practical use. Therefore the works on the developed analysis system were carefully tested (more than 100 diagrams were analyzed), and thus it has been shown the solvency of system (see detail results in section 3 ). The analysis system helps to be defined with a choice of a concrete methods class for the solving of separate subproblems. Thus, the developed system is a part of more general (common) system, which uses results of the analysis of inhomogeneous problem for the following synthesis of various methods in whole hybrid system solving the problem.

\section{TECHNIQUE OF THE ANALYSIS OF COMPLICATED PRACTICAL PROBLEMS}

The offered analysis technique is based on the scheme consisting of six consecutive stages (see Fig. 1). Thus if it is impossible to perform the next stage (for example, because of the information insufficiency) it is possible to return 
to one of the previous stages.

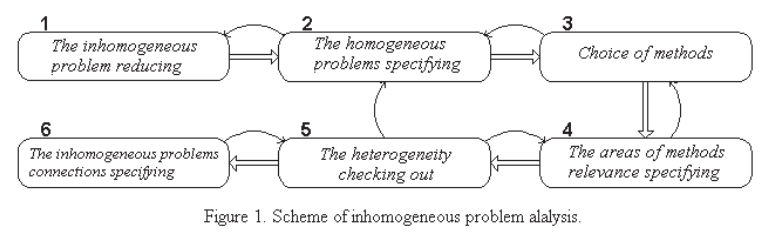

Figure 1. Scheme of inhomogeneous problem analysis.

Let's consider each of stages in more detail.

1. The inhomogeneous problem reducing. This stage is concerned with the system analysis of a problem. It is required to define the purpose, initial data about the problem and specify its identifier. Thus the attention addresses, mainly, on its composition and structure. The initial system is reduced to set of homogeneous problems. Thus the set of possible decompositions is constructed.

2. The homogeneous problems specifying. The procedure of specifying is informal and is carried out by the fashion designer, which, first of all, should increases a degree of own reliance in understanding the problem. Each homogeneous problem which is included in concrete decomposition is specified at this stage. The purpose of solving and initial data are also defined. Besides the qualifier is filled and the identifier is filled in the specifier. The display is carried out by a method of interview with the developer. During such interview you need to specify the rest of the specifier of the homogeneous problem, namely properties of development environment, problem environment, project, experts environment, measurements, the problem information, necessary for the solving, and properties of actions performed during the problem solving, and also properties of the plan of the problem solving. Both the graphic image (received on the first stage) and appropriate frame of the symbolical description are formed for each decomposition as the result of such procedure. After that it is possible to begin selection of a method(s), relevant to properties of the homogeneous problem.

3. Choice of methods. At present such procedure can not be written down by algorithm and consequently its realization concerns rather to knowledge and art of the fashion designer, than to subject of the theory. Nevertheless, world scientific and design engineering practices have the experience of recognition of situations developing after the specification of problems, solved during the project with the purpose of selection the tool, relevant to the situation for the further realization of this project. On the other hand, developers of those or other tools (for solving the problems of intellectual controlling and designing) have accumulated also knowledge of what classes of problems their clients applied software on. Finally, the intellectual controlling in most cases does not appear on an empty place, but always there is 
an experience of problems solving in a researched subject domain, accumulated by years in models and algorithms. Thus, it is supposed to compare the information received at the specification stage, to available knowledge of practical use of concrete methods (classes of methods) depending on concrete developing conditions of the problem solving. Number of key attributes of a separately taken homogeneous problem points to use of the concrete method (class of methods). This number we can consider as the degree of suitability of the given method for the solving of the considered homogeneous problem.

4. The areas of methods relevance specifying. When each for homogeneous problem the method is chosen, it is necessary to adjust the given method to the concrete problem. For this purpose it is necessary both to compare inputs - outputs of the problem to inputs - outputs of the method, and to adjust internal structure of the method so that the solution, generated by a method, would be relevant to the solution of problem. In case of failure it means that the problem is inhomogeneous (and should be considered as one more inhomogeneous problem with the appropriate analysis), or it is necessary to choose other method.

5. The heterogeneity checking out. The task of this stage is checking out if it is really necessary to use several methods for the problem solving, else the considered problem is homogeneous and there is no necessity to construct a hybrid system.

6. The inhomogeneous problems connections specifying. Now it is necessary to describe connections between inhomogeneous problems. First of all, such a description is necessary for the analyst in order to get a complete performance about a soluble problem, and for the fashion designer - developer also for the following development of interfaces at synthesis of independent methods in whole hybrid intellectual system.

Next section describes the system of the complicated practical problems analysis based on the above mentioned technique and world knowledge of practical using of six classes of methods (analytical methods, statistical methods, artificial neuronets, knowledge based systems, fuzzy systems and genetic algorithms) depending on conditions appearing during problem solving.

\section{SYSTEM OF THE COMPLICATED PRACTICAL PROBLEMS ANALYSIS}

The system GIMENEY-ANALYSIS is based on knowledge taken from the numerous references on mathematical methods of modelling and technologies of artificial intelligence and is submitted as rules in productive form. The taken knowledge originally was submitted in the tabulated form, and then is formalized in language of knowledge representation of the shell KBS KAPPA PC. 


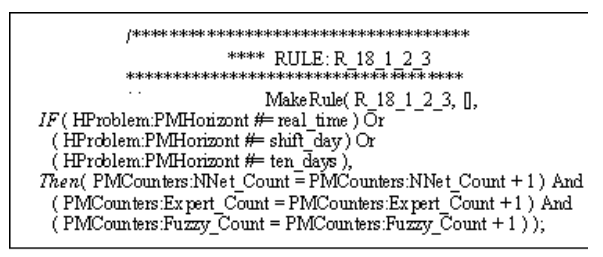

Figure 2. Knowledge representation for the homogeneous problem analysis.

Fig. 2 shows, that during formalization of knowledge we use the approach not "from a line ", when antecedents of rules would have huge quantity of variables, and the number of rules would be reduced up to six, that would result in unambiguity of the answers KBS (i.e. "yes" or "no"), but approach " from a column ", that has reduced the size of the left part of rules up to the several attitudes, and has resulted in increased of number of such simple rules up to 214, but has allowed to organize testing the knowledge base and two level results processing of the homogeneous problems specifications (see program GIM-H-CONSULTANT-2).

Using tools of the system the user can identify a inhomogeneous problem, reduce it to a set of homogeneous problems, construct set of decompositions, pick up set of relevant methods of modelling for each homogeneous problem. On Fig. 3 the architecture of system GIMENEY-ANALYSIS is shown.

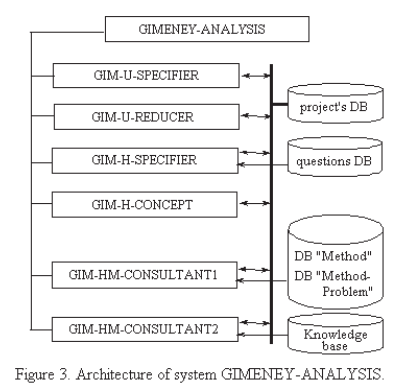

Figure 3. Architecture of system GIMENEY-ANALYSIS.

Fig. 3 shows, that the subsystems correspond to the described above scheme of the analysis of the inhomogeneous problem.

The program GIM-U-SPECIFIER carries out the specification of the inhomogeneous problem. Namely, defines the purpose, initial data about the inhomogeneous problem and its identifier, knowledge about MTD (man taking decision) and reasons of the solving, and also knowledge about connections of the given inhomogeneous problem with other inhomogeneous. The results of work are brought in base of the project.

The program GIM-U-REDUCER. Allows to build a decomposition graph of inhomogeneous problem on homogeneous (Fig. 4). Homogeneous problems 
in decomposition are designated by circles, and relations between them by arrows.

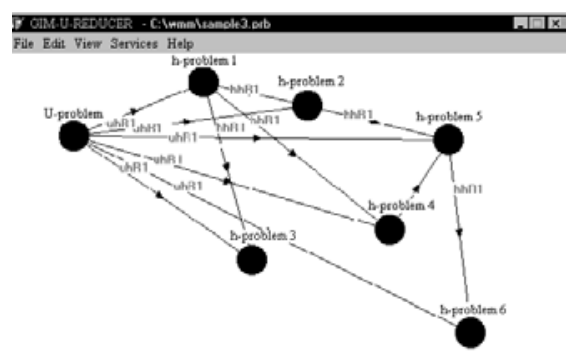

Figure 4. Screen shot of the program GIM-U-REDUCER.

The program GIM-H-SPECIFIER. The program is intended for the specification of homogeneous problems which are included in decomposition of inhomogeneous problem. The program uses base of the project and base of questions, which the developer should answer to specify each of homogeneous problems which are included in decomposition of a inhomogeneous problem. It is not necessary to respond at once, immediately on all questions. The questions are placed on 6 basic groups reflecting the all-round analysis of a problem. The list of questions is received as a result of the deep analysis of the special literature and systematization of the knowledge, accumulated in world practice, and experience of the analysis of practical problems with use of methods from six classes. It is accepted to name such approach to designing as "designing on the basis of knowledge", that certainly reflects subjective opinion of group of the authors on a problem of the specification of complicated practical problems.

The program GIM-H-CONCEPT. The program is intended for construction of semantic and conceptual models $(\mathrm{CM})$ for each of problems entering into frame-performance of decomposition of the inhomogeneous problem. Thus, after work of the program in memory of the computer are available formulated on language of conceptual modelling of the description inhomogeneous and homogeneous problems on each decomposition.

The program GIM-HM-CONSULTANT1. The program is intended to advice developer on a wide spectrum of questions, which can be formulated, using databases "Methods" and "Methods - problem". Two basic modes of the program operations are provided: advises with giving the information on chosen (for the analysis) problem from the decomposition frame and on one method (property, advantages and lacks, opportunity of hybridization with other methods, problems for which solving the method is intended theoretically and practice of use of this method) or on properties of a problem and two methods, that allows visually simultaneously to study the information on two methods, to compare it to properties of the problem, seeing thus lacks and advantages of methods. At this stage, as a rule, the user feels a neces- 
sity of hybridization. If during the analysis of a homogeneous problem and methods at this stage the user can independently accept the decision on use one or several methods for its solving, such information is saved in framepresentation. Otherwise, it is possible to take advantage of services of the program GIM-HM-CONSULTANT-2.

The program GIM-HM-CONSULTANT-2. It has been written in Delphi 5.0 , uses an exchange of the data with the program in language KAL (C- similar language of the shell KAPPA PC) and knowledge based system through DDE, developed in the shell KAPPA PC. The window with results of work of the program is given on Fig. 5 .

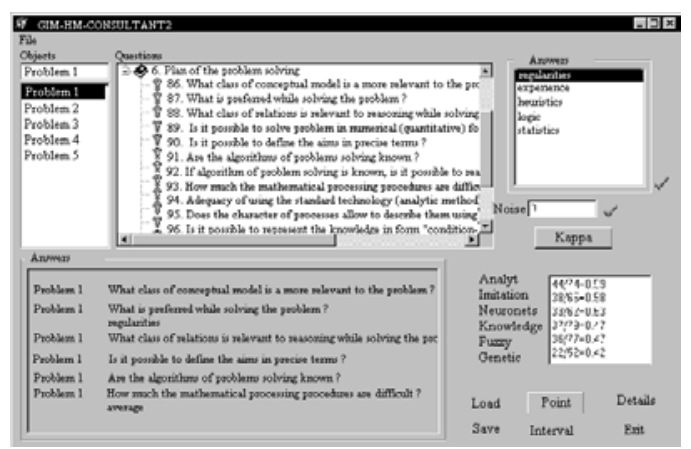

Figure 5. Screen shot of the program GIM-HM-CONSULTANT2 on the first detalization level.

In the top left corner you can see the list from six homogeneous problems, and the work goes with the chosen option "Problem 1". At the center of the top half you can see the questions, systematized on six sections, (on Fig. 5 it is possible to see a part of questions of the sixth group). In a right corner of the top half - alternatives of the answers on the allocated question. In the left part of the bottom half - the results of the answer of the developer on questions, in the right part of the bottom half - results of work KBS at the first level of detailed elaboration. In numerator of fraction - quantity of numbers (marks) obtained by the class of methods as a result of the specification of the problem by the user, and in the denominator - the greatest possible in system the quantity of numbers which can obtain the class.

The basic feature of the program is the two-level scheme of results processing of knowledge based system. On first, less detailed level, the results are given out for each of analyzed problems on all six classes of methods in numbers (marks). The larger numbers (in this case the mark is close to one), are "obtained" by the class, the higher degree of reliance can be at the user that the problem can be solved by methods from this class. However it is common that mark ratings are close to each other and in this case program offers services at the other more detailed level. In this case there are given out not only general numbers (marks), but also mark ratings obtained by the class of 
methods on each of six groups of questions (see Fig. 6). It is obvious, that in this case the user has more opportunities for the comparative analysis to define what moments from the problem specification can be neglected, and what moments are the key moments for the given project.

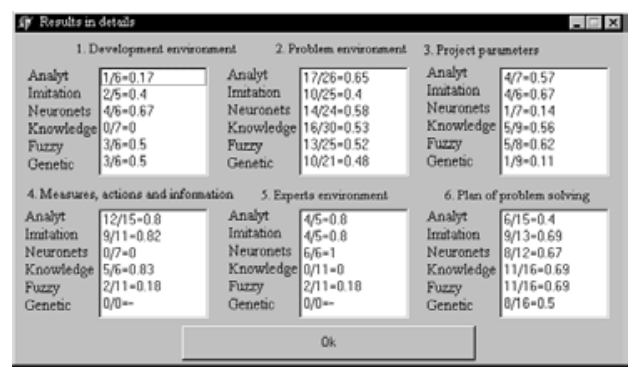

Figure 6. Screen shot of the program GIM-HM-CONSULTANT2 on the second detalization level.

\section{RESULTS OF EXPERIMENTS}

The quality (and principle) of system work was checked out by means of realization of numerous experiments and systematization of results. The experiments were carried out as follows:

- The sample (filled questionnaire) consistently for each of six classes was considered as a basis;

- The processing of the questionnaire was carried out according to the approach described in section 2. Thus it is considered, that the noise (distortion) is absent. The received value was fixed on the diagram on the ordinate axis. The quantity of the violent answers (at the beginning of experiments such quantity is equal to zero) is marked of ordinate (on an axis of abscissae.

- The value of noise was increased by one, and the NOISE was brought into the questionnaire, i.e. the answers (quantity of the violent answers is equal to value of noise) were changed in a random way. Thus the noise was generated by two ways (two separate, but complementary each other experiments). The first way consists in consecutive distortion of the one more $n$-s answer (where $\mathrm{n}$ is equal to the value of noise). So the value of noise (previous $n-1$ violent answers are kept) is increased each time. Such way of noise generation we name MOMENTARY NOISE. In the second case the noise is generated from beginning a new for all $n$ of the answers - MULTIPLE NOISE. After the noise submission the processing of the received questionnaire and fixing (on the diagrams) the results were made from beginning. The given stage was carried out cyclically till $n$ reached value 101 (i.e. before distortion of all answers in the questionnaire). 
The MULTIPLE noise is some kind of generalization, it combines all sets of experiments at MOMENTARY noise. Therefore dependences in MULTIPLE noise in the greater degree can apply for law in comparison with MOMENTARY noise. However, the MOMENTARY noise shows more precisely revealed dependence and is irreplaceable in disputable situations (i.e. when dependence very difficultly to find out, or there are doubts in the revealed dependence). The example of MULTIPLE noise at initially taken sample analytical methods is shown on Fig. 7 .

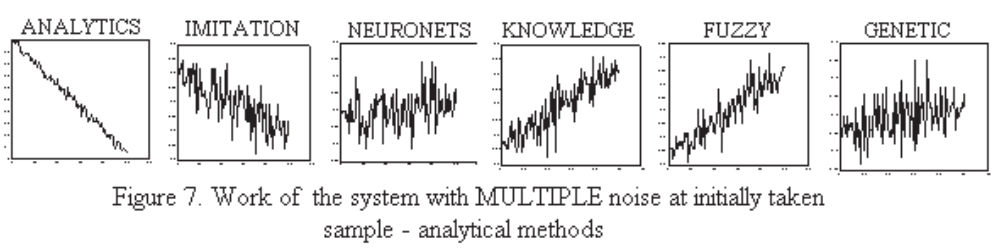

Figure 7. Work of the system with MULTIPLE noise at initially taken sample - analytical methods.

Having analyzed the received diagrams it is possible to tell, that 3 groups of classes are obviously allocated: 1) Analytical and imitating methods; 2) Knowledge based and fuzzy systems; 3) Genetic algorithm and artificial neuronets. In the first of the allocated groups it is possible to note, that when the applicability degree of one methods class (analytical or imitating) decreased the applicability degree of other (second) methods class immediately also decreases. Thus the applicability degree of classes from the second group (knowledge based and fuzzy systems) unequivocally increases. It is possible to conclude, that in this case the applicability degree of classes from the third group decreases (in a number of cases such behaviour is possible to be considered as a random).

By analogy with the connection between methods classes from the first group the connection in the second group is also observed, i.e. when we decrease the applicability degree of one of methods classes (knowledge based or fuzzy systems) the applicability degree of the second methods class immediately also decreases. Thus the applicability degree of classes from the first group (analytical and imitating methods) unequivocally increases. Besides, it is possible to tell about behaviour of the third group of classes (but not too confidently), that increasing here is observed.

When the applicability degree of neuronets is decreased, the decreasing at genetic algorithms and in the first group is also observed, and in the second group - increasing is observed. Decreasing of the applicability degree of genetic algorithms leads to decreasing at neuronets and in the second group and increasing is observed in the first group.

Thus, it is visible that the most precise and unequivocal connections are allocated between the first and second groups (both inside separate group, and between groups), and last group most of all " is covered with mystery ". 
Such "mystery" ("mystery" is understood as impossibility in many cases precisely to define applicability or non-applicability of the given methods class), probably, follows from novelty and insufficiency of knowledge (in world practice in general and in the knowledge base, put in system, in particular) in the specified areas.

One more result of system is the fact of "good" results (means the good degree of tolerance to handicaps) at mistakes 10-15\% and "satisfactory" at mistakes up to $20 \%$, in separate (rather rare) cases the mistakes can reach $40 \%$ (at preservation of the "correct" answer).

\title{
5. THE CONCLUSION
}

This paper shows the actuality of performing the analysis for the best understanding of complicated problems. The neglect of the analysis can become the reason of huge losses, since the probability to be initially directed on incorrect way of the problem solving is increased. This paper describes the concrete offer to avoid a similar situation. For this purpose the original technique of the analysis of a complicated inhomogeneous problem is developed, the appropriate software is described. Thus, offered technique and system of the analysis are based on world experience of use of modern tools and methods of artificial intelligence. The received graphic dependences of rating the problem to a concrete class of methods from volume of noise, brought into the description, have shown sufficiency and consistency of knowledge base for the inhomogeneous problem analysis even in conditions with low and average noise (distortion) in the problem description. The analysis system helps user to be defined with a choice of a concrete methods class for the separate subproblems solving. The offered methodology and system can be used independently and as a part of problem-structural technology of hybrid intellectual systems development.

\section{REFERENCES}

[1] A.V. Kolesnikov. Hybrid intellectual systems. Theory and technology of development. $\mathrm{SPb}$ GTU, 2001.

[2] U.V. Kostov. The complex approach to mind modelling of the man activity. KII 98, 1, 1998.

[3] E.A. Trahtengerc. Multiagent system of decisions support. The theory and control systems, 5, 1998.

\section{Sudètingų praktinių uždavinių sistemos analizė}

\author{
A.V. Kolesnikov, O.P. Fedorov
}

Pasiūlyta nehomogeninio uždavinio sisteminès analizès originali metodika. Ji apima redukcijos i homogenines dalis etapus, parenka atitinkamus metodus ir modelius. Sukauptos teorinès žinios ir ekspertu igūdžiai pritaikomi priskiriant kiekvieną homogeninị uždavinị vienai arba kelioms modeliavimo metodụ alternatyvioms klasėms. Teorinių žinių testavimas duoda pakankamą ir nuoseklią analizę realizuojant nehomogenines sistemas, esant mažiems ir vidutiniams netikslumams problemos apibūdinime. 